\title{
Is patenting of technical inventions in university sectors impeding the flow of scientific knowledge to the public? a case study of South Africa
}

\author{
Louis Mitondo Lubango*, Anastassios Pouris \\ Institute for Technological Innovation, Faculty of Engineering, Built Environment and Information Technology, University of Pretoria, Pretoria, South Africa
}

\section{Keywords:}

Patents

Citation

Knowledge flow

South Africa

\begin{abstract}
A B S T R A C T
There is growing pessimism among certain academics and policy scholars that the conduct of innovation-related activities (e.g., patenting, transfer, and commercialization of scientific or technological development) may be hampering the production and dissemination of public science. This paper investigates whether the production of scientific articles while concurrently patenting technical inventions can be mutually supportive. In an analysis of 70 patents obtained from the USPTO, EPO, and WIPO, for inventions or co-inventions by scientists employed by South African universities from 1994-2006, 58 patents (82\%) overlapped, i.e., formed pairs with scientific articles. We found that authors tended to patent and publish simultaneously, so the same intellectual work informed both products. Our findings could be used to promote university-industry technology in many innovation systems.
\end{abstract}

Crown Copyright (c) 2010 Published by Elsevier Ltd. All rights reserved.

\section{Introduction}

In universities, the demand for greater relevance of research to societal needs has stimulated interest in patentable inventions. It has also raised controversial issues about tradeoffs between academic productivity and academic entrepreneurship [1]. It was recently reported in South Africa and some developed economies that inventive academics were also academically excellent in terms of publications productivity, research performance, and international recognition by peers [2-5]. This study takes our 2009 findings [2] a step further.

In this study we consider the following issues: (1) Do patents and publishing really reinforce each other? (2) Does patenting of technical inventions in university sectors impede the flow of scientific knowledge to the public? (3) What are the characteristics of the diffusion of the South African universities' patented inventions? These questions are explored empirically based on the assumption that patenting technical inventions and producing scientific

\footnotetext{
* Corresponding author.

E-mail address: Lmitondo12@yahoo.com (L.M. Lubango).
}

articles do not pose a conflict in universities. This research combines patent citations, bibliometrics, and archives analyses.

\section{Literature review}

A patent contains comprehensive information on the technical properties of an invention and its linkages to other technologies and to science. Current bibliometric models of knowledge spillover support the idea that citations from one patent to another can proxy how an invention builds on prior inventions, i.e., flows of knowledge from previous to the actual invention [6-13]. In the same manner, references to scientific papers in patents can indicate spillovers of knowledge from science to technology (science linkages). The later linkages are often used to indicate to what extent technological progress stands on the shoulders of public research as it evolves [8-24].

This work expands the concept of a patent citation network. Indirect and direct citations as well as forward and backward citations in the citation networks are included in the citation network analysis. This approach gives a perspective on the phenomenon of knowledge flows. 
Table 1

Citation characteristics of USPTO patent-based pairs: backward and first generation forward citation profiles.

\begin{tabular}{|c|c|c|c|c|c|c|c|}
\hline \multicolumn{4}{|c|}{ Focal patents (total: 30 ) } & \multicolumn{4}{|c|}{ Focal journal articles (total: 30 ) } \\
\hline \multicolumn{2}{|c|}{$\begin{array}{l}\text { Backward } \\
\text { citation }\end{array}$} & \multicolumn{2}{|c|}{$\begin{array}{l}\text { Forward } \\
\text { citation }\end{array}$} & \multicolumn{2}{|c|}{$\begin{array}{l}\text { Backward } \\
\text { citation }\end{array}$} & \multicolumn{2}{|c|}{$\begin{array}{l}\text { Forward } \\
\text { citation }\end{array}$} \\
\hline Article & $\overline{\text { Patent }}$ & Article & $\overline{\text { Patent }}$ & Article & $\overline{\text { Patent }}$ & Article & Patent \\
\hline 0 & 219 & 0 & 41 & 511 & 0 & 251 & 0 \\
\hline
\end{tabular}

A direct citation link exists between two patent families if a patent family cites or receives a citation by another $[8, \mathrm{p}$. 1592]. If a cited patent family in turn cites another family, an indirect citation chain is established between the first and last patent families. A co-citation link occurs if two or more families are cited together by another patent family. Indirect citations differ from scholarly publication citations, as references are strictly limited to the nearest, that is, most recent, prior cite. A forward citation for Patent $\mathrm{X}$ is a reference made by Patent $Y$ to Patent $X$. A backward citation by Patent $X$ is a reference that Patent $X$ makes to another Patent $Z$. The forward citation encompasses both the direct and the indirect citations (i.e. second generation).

The technological foundation of citing patents should therefore include both the most recent development cited and the basic principles from earlier patents. The indirect linkages captured by citation chains can thus reveal ties to a basic patent. Given that Patent A cites exclusively Patent $\mathrm{B}$, which in turn solely cites Patent $\mathrm{C}$, it is possible to assume a unique development path that could stem from $C$ and leads to A. Patents A and B could be technological improvements of $C$. It appears reasonable, then, that $A$ could not only build on B, but also in the same way on C. Accordingly, it would be reasonable to establish identical proximities of A versus B, B versus $C$, and A versus C.

For a given set of patents, both the forward and backward citations to (or by) other patents and non-patent documents should count in the citation network. The nonpatent documents are generally a reference to scientific input in patents. They mainly include Institute for Scientific Information (ISI) articles and other sources, such as hard and/or electronic copies of books of abstracts or proceedings of scientific or technical conferences that do not appear in ISI data. They may also include scientific or technical journals in university or government libraries, non-scientific publications, product specifications, technological disclosure bulletins and trade journals, articles in company journals, local scientific journals, or international academic periodicals. They can serve as metrics of the industrial relevance of research. They can also reveal trends

\section{Table 2}

Citation characteristics of WIPO patent-based pairs: backward and first generation forward citation profiles.

\begin{tabular}{|c|c|c|c|c|c|c|c|}
\hline \multicolumn{4}{|c|}{ Focal patents (total: 23 ) } & \multicolumn{4}{|c|}{ Focal journal articles (total: 22 ) } \\
\hline \multicolumn{2}{|c|}{$\begin{array}{l}\text { Backward } \\
\text { citation }\end{array}$} & \multicolumn{2}{|c|}{$\begin{array}{l}\text { Forward } \\
\text { citation }\end{array}$} & \multicolumn{2}{|c|}{$\begin{array}{l}\text { Backward } \\
\text { citation }\end{array}$} & \multicolumn{2}{|c|}{$\begin{array}{l}\text { Forward } \\
\text { citation }\end{array}$} \\
\hline Article & $\overline{\text { Patent }}$ & Article & $\overline{\text { Patent }}$ & Article & $\overline{\text { Patent }}$ & Article & $\overline{\text { Patent }}$ \\
\hline 226 & 64 & 0 & 0 & 472 & 0 & 183 & 0 \\
\hline
\end{tabular}

Table 3

Overall citation profiles of pair 1 (first generation).

\begin{tabular}{lll}
\hline Frequency & Focal patent & Focal article \\
\hline Bkwd citation to article & 0 & 42 \\
Bkwd citation to patent & 9 & 0 \\
Fwd citation by article & 0 & 4 \\
Fwd citation by patent & 5 & 0 \\
\hline
\end{tabular}

of various linkages between science and technology and the differences in international and domestic utilization of industrial research produced by the science base.

Scientific and technological networks are distinct communities in which knowledge flows are bi-directional, capable of overlapping, and thus mutually reinforcing. Each flow shapes the other during the spillover of ideas. Using a bibliometric approach, Murray [4] reported that the processes that shaped those overlaps and co-evolution range from continued involvement of key scientists in further patenting and technology development to firm founding, consulting, mentoring, and informal scientific advising.

During the period when scientific and technical constructs overlap, scientific ideas represent not only new insights but also new technical solutions [25]. The same idea can be different for a patent and for a related paper, thus constituting a patent-paper pair [4]. The two documents might thus present the same idea in texts that are very distinct, such as a paper that explains experimental results and a patent that defines utility and makes claims.

Thus pairs can make valuable distinctions between the performances of institutions even though they represent one underlying idea. They also perfectly constitute an instant when science and technology overlap. They epitomize the intertwined and co-evolutionary nature of scientific and technical ideas.

Pairs can be found through a careful analysis of the content of patents and papers (by comparing abstracts, claims, introduction, methods, discussions, conclusions, and applications). A pair forms a reliable basis for traditional quantitative bibliometric analyses of innovation, spillovers, and networks $[23,24]$.

Based on the above-described citation model of knowledge spillover, the present study develops a hypothesis that explores whether through pairs, science and technology or basic and industrial research can co-evolve, cross-fertilize, and undergo broader flows.

\section{Research methodology}

Patents from South African universities, as well as foreign patents that list professors from South African universities as inventors or co-inventors-both types filed

Table 4

Overall forward citation profile of pair 1 (second generation).

\begin{tabular}{lll}
\hline Frequency & Focal patent & Focal article \\
\hline Fwd citation by article & 0 & 11 \\
Fwd citation by patent & 8 & 0 \\
\hline
\end{tabular}




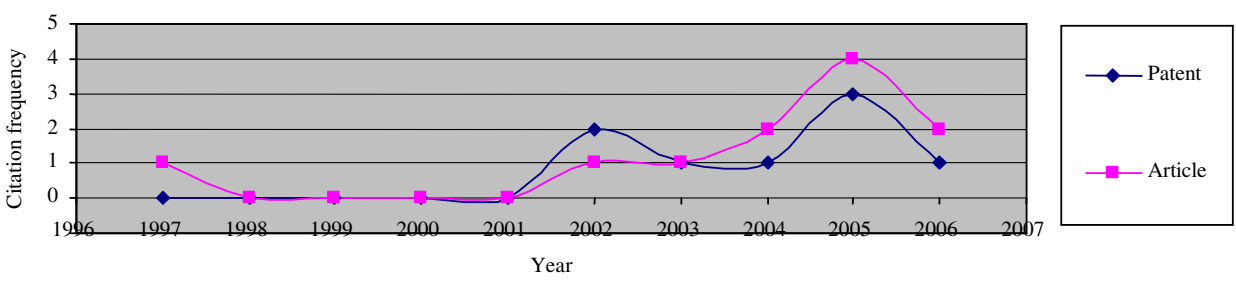

Fig. 1. Diffusion of knowledge of pair 1 (first generation).

at CIPRO, EPO, WIPO and USPTO-were collected. Abstracts and claims of patents were compared to the content of journal articles to identify pairs. Citation data for articles were obtained from the citation index using the names of the inventors, affiliation, and period of publication/citation for electronic search. Citations where an author or an inventor cited himself were not considered. Names, addresses, and affiliations of the author or co-authors were obtained from the corresponding journal article's front pages. Further mechanisms of linkages between universities and industries were obtained from semi-structured interviews with South African senior patent officers.

\section{Results and discussion}

A population of 70 patents, covering the period from 1996 to 2006, was obtained from the USPTO and WIPO databases. The patents mainly pertained to biotechnology, polymers, signal processing, analytical chemistry, materials processing, drug/pharmaceuticals, machinery and tools, mineral processing, separation, hard materials, and FischerTropsch technologies. All patents listed South African university professors as inventor/co-inventors or assignee/ co-assignees. The bibliographic data revealed that most patents were assigned to South African universities. Some patents were licensed by South African universities to South African and/or to foreign industries. Other patents were applied by South African professors individually. Patent applications at CIPRO for all South African tertiary institutions within the investigation period totaled 280.

Most patents were first applied locally (where application fees were significantly lower and thus more affordable) and then abroad (where application fees are much more costly). Some patents applied or owned abroad by local or foreign industries were improved versions of local applications. Most applications filed abroad were funded by local or foreign industries. Others were just the outcomes of contract work between South African or foreign industries and South African professors. This evidence was revealed by a semi-structured interview conducted with certain heads of the South African University Patent Offices.

\subsection{General characteristics of the pairs}

Of the 70 patents, 58 formed pairs (see Tables 1,2). The same knowledge disclosed in each patent was also published in an article and thus formed patent-paper pairs.

The USPTO patents heavily cited other patents (all from industry) and were mostly cited by other patents (from industry). The corresponding articles only cited articles and were mostly cited by other articles. These patents hardly cited articles. Inventors and attorneys might be constrained to sketch patent applications that way to comply with the industrial applicability of the claimed invention criteria for granting a patent that is stronger at the USPTO than at EPO. The focal patents published by WIPO tended to cite more articles than patents. The corresponding focal articles of both types of focal patents cited articles exclusively and were cited by articles. The following case studies focused only on the USPTO-based pairs.

\subsection{Extended case studies}

Among the 58 pairs, four pairs for each of the following sectors were chosen for detailed investigation: polymer membrane (for water-purification), circuit for generating minimum supply voltage, genetic engineering (cloning), or biotechnology and mineral processing (flotation). The patent and the article that comprised a pair are referred to as focal patent and focal article, respectively.

\subsubsection{Pair 1: polymer membrane for water-purification device}

The knowledge disclosed in this pair (both the focal patent and focal article) detailed the composition and use of a polymer membrane in a water-purification device. The device was invented by a professor from a Stellenbosch University (SUN) in South Africa. The focal patent was filed

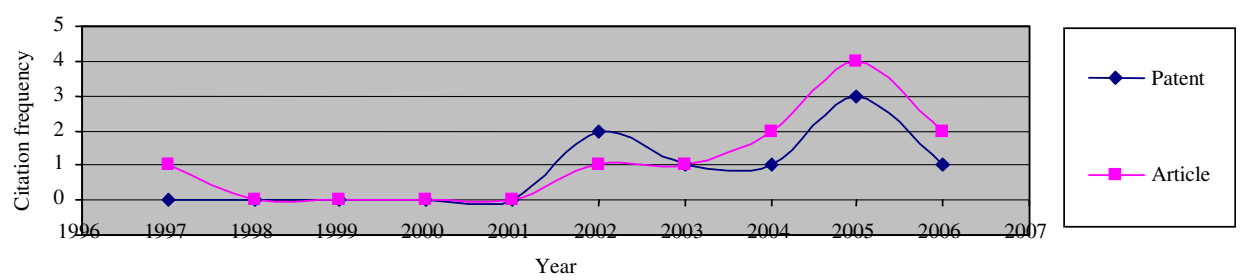

Fig. 2. Diffusion of knowledge of pair 1 (second generation). 
Table 5

Overall citation profile of pair 2 (first generation).

\begin{tabular}{llc}
\hline Frequency & Focal patent & Focal article \\
\hline Bkwd citation to article & 0 & 9 \\
Bkwd citation to patent & 1 & 0 \\
Fwd citation by article & 0 & 10 \\
Fwd citation by patent & 5 & 0 \\
\hline
\end{tabular}

Table 6

Forward citation profile of pair 2 (second generation).

\begin{tabular}{lll}
\hline Frequency & Focal patent & Focal article \\
\hline Fwd citation by article & 0 & 9 \\
Fwd citation by patent & 7 & 0 \\
\hline
\end{tabular}

at the USPTO in 1995 and was assigned in 1997 to Water Research Commission (a South African research funding organization). The focal article was published in the Journal of Membrane Science (1996; 113 (2):275-284). Table 3 summarizes the backward and direct forward citations of both the focal patent and the article.

Table 4 summarizes the indirect forward citations of both the focal patent and focal article. In the first generation, the focal patent cited nine patents, all from foreign industries, and was directly cited by five patents (all from foreign industries). In the second generation, the knowledge disclosed in the focal patent was cited eight times by patents (all assigned to foreign industries). No non-patent sources were cited, and no non-patent sources cited this patent. This suggests that the patented technology originated from industry, was developed in a university, and then absorbed by industry.

The focal article was co-authored by four individuals: two were employed by SUN, one of whom invented the focal patent. The third co-author was a professor in a Canadian university, and the fourth was a professor in a Russian university. The focal article cited 42 articles and was cited by 4 other articles. The article did not cite any patents nor was it cited by any patents. In the second generation (i.e., indirect citations), the knowledge from the focal article was cited 11 times by articles with authors from academia (none from SUN) and did not receive any citations by a patent. This suggests that the knowledge disclosed in the public science domain flowed via the focal article.

Fig. 1 shows the diffusion patterns of the focal patent and article in the first generation. The patent was cited once in 1997 but the article was not cited. From 1998 to 2003, the diffusion of the knowledge disclosed in both the focal patent and paper looked similar in that period. Both the patent and the article were cited once in 1999 and 2000. From 2003 to 2006, the diffusion patterns differed again. The patent was cited once in 2004 and in 2005 and the article was only cited two times in 2006.

Fig. 2 shows the diffusion patterns of both the focal patent and article in the second generation. The knowledge disclosed in the focal patent was not cited from 1997 to 2001. However, it was cited twice in 2002 by patents, three times in 2004, and once in 2003, 2004, and 2006 by patents. The knowledge disclosed in the focal article was cited once in 1997 by an article, but not cited at all from 1998 to 2001. Again, it was cited once in 2003 twice in 2004, four times in 2005, and twice again in 2006 by articles.

The flow of the knowledge through patent and article seemed different in both generations: slower through patent and faster through public.

\subsubsection{Pair 2: CMOS circuit for minimum supply voltage technology}

The knowledge disclosed in pair 2 (both focal patent and focal paper) described some modifications to translinear circuit topologies through use of non-saturated MOS transistors operating in weak inversion. The configuration was claimed to be suitable for static and dynamic analog signal processing circuits in mixed-signal chips fabricated using digital CMOS technology and operating at the minimum possible supply voltage.

The focal patent was filed at the USPTO in 1997 and assigned to US Philips Corporation in 1998. The focal article was published in IEEE Transaction on Circuit and Systems II: Analogue and Digital Signal Processing (2000; 47 (12): 1560-1564). Table 5 summarizes the backward and forward citations of both the focal patent and focal article.

Table 6 summarizes the forward citations of both the focal patent and article. The invention was made by three professors from University of Pretoria (UP). The complete application filed to USPTO and assigned to US Philips Corporation was an improved version of a provisional patent application filed at CIPRO by the inventors. This suggests that the CIPRO application was licensed or sold to industry by the university and/or by the inventors for industrial exploitation by Philips. This could also be regarded as a linkage between foreign industry and a South African university's inventor(s).

In the first generation, the patent cited only one patent (from a foreign industry) and was cited by five patents, all

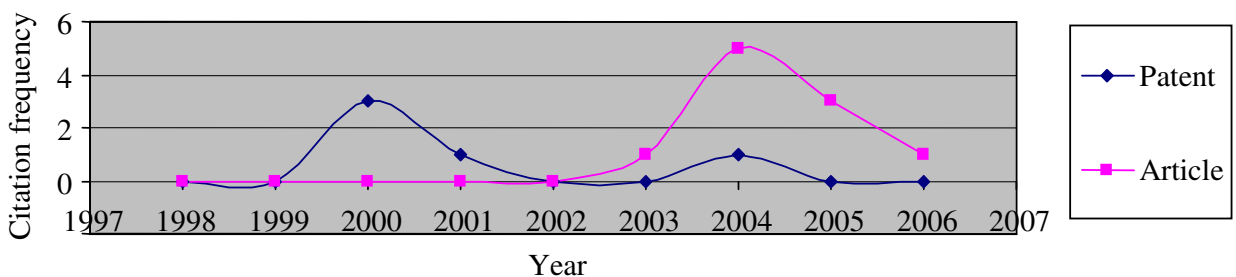

Fig. 3. Diffusion of knowledge of pair 2 (first generation). 


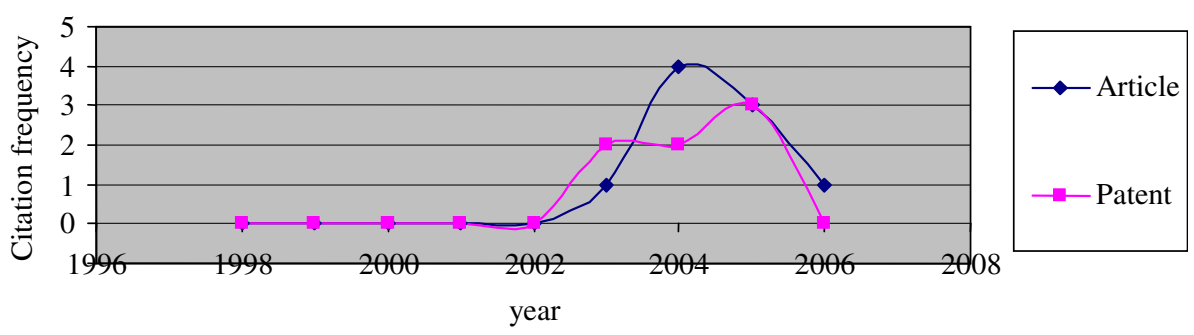

Fig. 4. Diffusion of knowledge of pair 2 (second generation).

Table 7

Overall citation profile of pair 3 (first generation).

\begin{tabular}{lll}
\hline Frequency & Focal patent & Focal article \\
\hline Bkwd. citation to article & 0 & 37 \\
Bkwd. citation to patent & 3 & 0 \\
Fwd. citation by article & 0 & 1 \\
Fwd. citation by patent & 0 & 0 \\
\hline
\end{tabular}

Table 8

Forward citation profile of pair 3 (second generation).

\begin{tabular}{lll}
\hline Frequency & Focal patent & Focal article \\
\hline Fwd citation by article & 0 & 1 \\
Fwd citation by patent & 0 & 0 \\
\hline
\end{tabular}

from foreign industries. The focal patent did not cite any non-patent, and it was not cited by any non-patent sources. This suggests that the knowledge disclosed in the focal patent flowed from industry to industry via university.

The focal article was co-authored by five individuals. Three were professors employed at UP-two of them the co-inventors of the focal patent. The other two co-authors were researchers from the Circuit Research Institute in Eersel, Netherlands. Another author was from the Swiss Electric \& Microtech SA, Neuchatel, Switzerland (Ed: three + two + "another" $=6$ authors??). The focal article cited nine articles and was cited ten times by articles in the first generation. The article did not cite any patents, and it was not cited by any patents. This suggests that the knowledge disclosed in the focal article flowed within public science via university.

In the second generation, the focal patent was cited seven times by patents from industry and was not cited by any articles. This suggests that the knowledge flowed from industry to industry via university. The focal article was cited nine times by articles and was not cited by any
Table 9

Overall citation profile of pair 4 (first generation).

\begin{tabular}{lcc}
\hline Frequency & Focal patent & Focal article \\
\hline Bkwd. citation to article & 0 & 11 \\
Bkwd. citation to patent & 25 & 0 \\
Fwd. citation by article & 0 & 1 \\
Fwd. citation by patent & 5 & 0 \\
\hline
\end{tabular}

Table 10

Forward citation profile of pair 4 (second generation).

\begin{tabular}{lcl}
\hline Frequency & Focal patent & Focal article \\
\hline Fwd. citation by article & 0 & 1 \\
Fwd. citation by patent & 11 & 0 \\
\hline
\end{tabular}

patents. This suggests that knowledge flowed into the public sciences via university.

Fig. 3 shows the diffusion patterns of the knowledge disclosed in the focal patent and article in the first generation. The pair was not cited from 1996 to 1999. The patent was cited three times in 2000, once in 2001, and again in 2004. The article was cited once in 2003, five times in 2004 , three times in 2005, and once in 2006.

Fig. 4 shows the diffusion patterns of the knowledge disclosed in the focal patent and article in the second generation. The pair was not cited from 1998 to 2002. In 2003 the article was cited once, and the patent two times. In 2004 the article was cited four times, and the patent two times. In 2005 the patent was cited three times; the article was not cited. In 2006, the article was cited once, but the patent was not cited.

\subsubsection{Pair 3: genetic engineering/biotechnology}

The knowledge disclosed in pair 3 (both focal patent and focal paper) described an isolated nucleotide comprising a sequence that encoded eukaryotic malate permease from

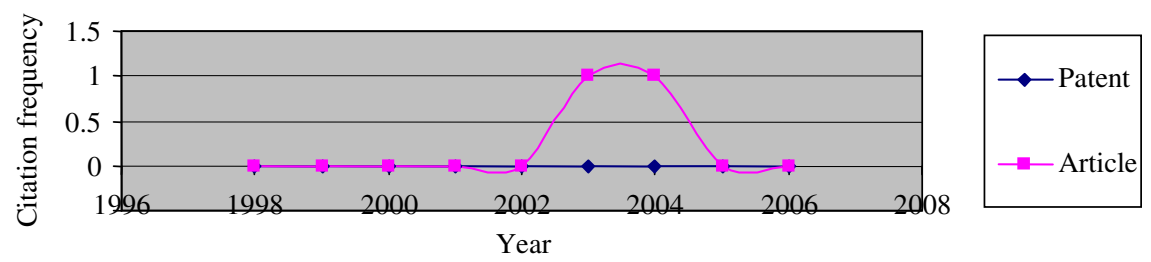

Fig. 5. Diffusion of knowledge of pair 3 (first generation). 


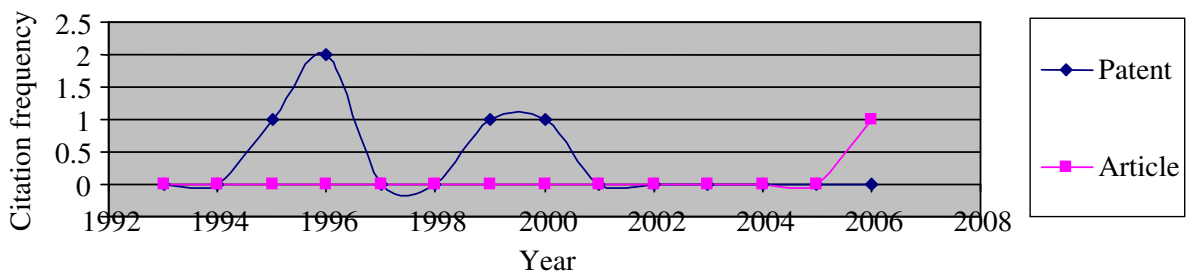

Fig. 6. Diffusion of knowledge of pair 4 (first generation).

schizosaccharomyces pombe, which mediated the uptake of $\mathrm{L}$-malate succinate and malonate.

The focal patent was filed at the USPTO in 1998 and was issued to SUN in 2001. The focal article was published in Food Research International (1999; 31(1): 37-42). Table 7 summarizes the backward and forward citations of both the focal patent and article.

Table 8 summarizes the forward citations of both the focal patent and article in the second generation.

The invention was made by six professors; three of them were foreign visitors or collaborators at SUN. One of those three was employed as a director in a Canadian wine corporation. This suggests a linkage between the inventors and industry. One of the six was from a Thailand university, and others worked at SUN. The provisional application filed at CIPRO, was assigned to SUN; the complete application made at the USPTO was assigned to SUN. This patent was not licensed nor sold to an industry. The focal patent cited three patents (all from foreign industries) but was not cited.

The focal article was co-authored by five individuals. Four of these were co-inventors of the focal patent. One of the five co-authors was employed by SUN. The focal article cited 37 articles and was cited three times by articles. Two of those citing articles were self-citations and thus did not count. The article did not cite any patent and it was not cited by any patent.

Fig. 5 shows the diffusion patterns of the knowledge disclosed in the focal patent and article in the first generation. The diffusion patterns were significantly different. The focal patent was not cited at all, and the focal article was only cited once in 2003 and once in 2004. The diffusion of knowledge in the second generation was negligible and is not reported here.

\subsubsection{Pair 4: flotation column}

The knowledge disclosed in pair 4 (both focal patent and focal article) described a new configuration of the flotation column that improved the mixing quality of the column and the resulting efficiency in the recovered minerals. The focal patent was invented by a professor from University of Witwatersrand (Wits). It was filed at the USPTO in 1997 and issued in 1994 to Multotec Cyclones (Pty) Limited, a minerals processing industry operating in South Africa. The focal article was published in a bulletin from the Canadian Institute of Mining, Metallurgy and Petroleum, CIM Bulletin (1993; 86 (968): 138-143). Table 9 summarizes the backward and forward citations of both the focal patent and article.

Table 10 summarizes the forward citations of both the focal patent and article in the second generation.

In the first generation, the focal patent cited 25 patents (all from industry) and was cited five times by other patents (all from industry). The focal patent did not receive any citations in the second generation. The patent did not cite any non-patent sources and was not cited by any nonpatent source. This suggests that the knowledge disclosed in the focal patent flowed from industry to industry via university.

The focal article was co-authored by three individuals. One of the authors was the inventor of the focal patent and the remaining two were from industry. The focal article cited eleven articles and was also cited by one article. This suggests that the knowledge disclosed in the focal article flowed from public science to public science via university.

In the second generation, the knowledge disclosed through the focal article was not cited at all, while the knowledge disclosed in the focal patent was cited eleven times.

Fig. 6 summarizes the diffusion patterns of the knowledge disclosed in the focal patent and article in the first generation. The diffusion patterns were significantly different. The focal patent was cited once in 1995, twice in 1996, and once in 1999, 2000, and 2006.

Fig. 7 summarizes the diffusion patterns of the knowledge disclosed in the focal patent and article in the second generation. The focal article was not cited at all. The focal

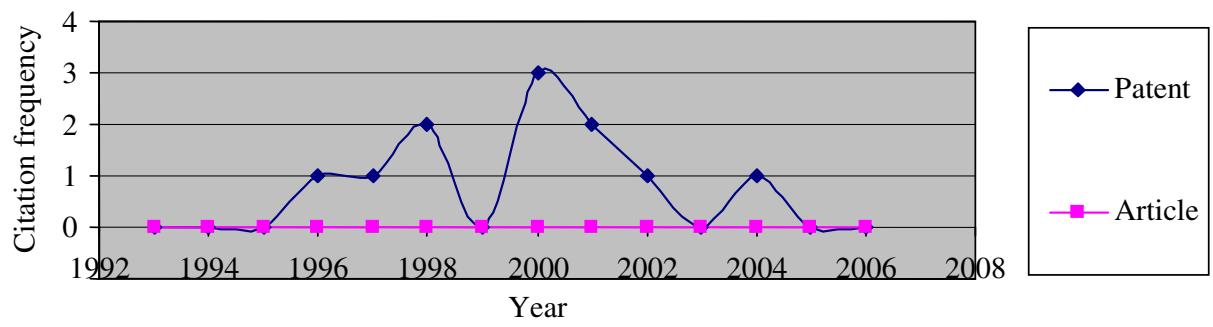

Fig. 7. Diffusion of knowledge of pair 4 (second generation). 
patent was cited once in 1996 and 1997, twice in 1998, three times in 2000, twice in 2001, and once in 2002 and 2004.

\section{Conclusion}

This study was part of a Ph.D. project that analyzed the dynamics, challenges, benefits, and risks associated with patenting inventions in universities. This research has led to publication of three papers thus far.

The first paper [26] reported on an investigation into the effects of employing researchers with previous industry work experience. The research found that such employment is an effective mechanism for increasing the core skills of technological innovation in mainstream universities, which ultimately translates into higher inventive capacity. Most inventive professors had previous industry work experience.

The second paper [2] reported that patenting and the publishing of scientific articles or leading other academic activities do not necessarily result in conflict. Most professorinventors had larger social networks that included prominent scientists, engineers, and others in academia and industry (especially where they had worked previously), which (among other things) promotes knowledge spillover and enhanced research quality. The publication performance of professor-inventors was superior to that of professornoninventors. Furthermore, professor-inventors were all NRF-rated (the National Research Foundation rates the country's good researchers into categories A, B and C) [Ed: define please], meaning they were perceived by their national and international peers as leading or established scholars in their disciplines and beyond, based on their teachings, supervision, and publication output, in addition to their active involvement in patenting, licensing, etc.

This paper (the third) aimed to understand the mechanisms through which the production and flows of patent and articles support each other. All the evidence confirms that far from being in conflict, patents and articles in South African universities overlapped, cross-fertilized, and coevolved. A population of 70 patents invented and/or coinvented by South African university professors, was collected from the USPTO, EPO, and WIPO. Fifty-eight patents from the aforementioned population could be paired with papers or articles. In other words, the knowledge disclosed in each patent was also published in an article, thus forming patent/paper pairs.

The analysis of forward and backward citation patterns of pairs-polymer membrane, signal processing, genetic engineering, and mineral processing sectors-reveals that:

- technical knowledge flowing from industry to university can subsequently be successfully diffused through articles or through patents

- scientific knowledge disclosed through an article or a paper can subsequently be successfully diffused through an article or a patent.

Interviews with certain senior South African University patent officers, and an analysis of the patent application ownership history, provided further evidence that in addition to forming pairs, inventors interact with industry through other means, such as licensing, contracts, and collaborative research. The citation profiles of all pairs investigated showed that a focal patent produced in South African universities strongly tended to build on the prior article from industry (foreign). This suggests that technological knowledge production and flow was not restrained within the boundaries of industries. It was absorbed, transformed, accumulated, stored, and used by universities. The South African university patents were absorbed mostly by foreign industry. Only a few were absorbed locally, through licensing or sale.

The issue of whether some researchers might sacrifice intellectual achievement in order to work on patents is outside the scope of this article, and would be a useful topic for future research. The major finding here is that the production of patents and publications tends to co-exist in the same author, and the same intellectual work can inform both products by the same author.

The findings could be used to promote knowledge transfer and diffusion between university and industry within the South African national innovation system and elsewhere.

\section{Acknowledgement}

We would like to thank Anthony J. Wiener for his constructive observations on this work.

\section{References}

[1] Wallmark JT. Inventions and patents at universities: the case of Chalmers University of Technology. Technovation 1977;17(3): 127-39.

[2] Lubango LM, Pouris A. Is patenting activity impeding the academic performance of South African university researchers? Technology in Society; 2009:315-24.

[3] Van Looy B, Ranga M, Callaert J, Debackere K, Zimmermann E. Combining entrepreneurial and scientific performance in academia: toward a compounded and reciprocal Mathew effect? Research Policy 2004;33:425-41.

[4] Murray F. Innovation as co-evolution of scientific and technological networks: exploring tissue engineering. Research Policy 2002;31: 1389-403.

[5] Tijssen RJW. Is commercialization of scientific research affecting the production of public knowledge? Global trends in the output of corporate research articles. Research Policy 2004;33:709-33.

[6] Tijssen RJW. Global and domestic utilization of industrial relevant science: patent citation analysis of science-technology interactions and knowledge flows. Research Policy 2001;30:35-54.

[7] Harhoff D, Scherer FM, Vopel K. Citations, family size, opposition and the value of patent rights. Research Policy 2003;32:1343-63.

[8] Von Wartburg I, Treichert T, Rost K. Inventive progress measured by multistage patent citations analysis. Research Policy 2005;34: 1591-607.

[9] Braam RR, Moed HF, Van Raan AFJ. Mapping of science by combined co-citation and word analysis. I: structural aspects. Journal of the American Society for Information Science 1991;42:233-51.

[10] Braam RR, Moed HF, Van Raan AFJ. Mapping of science by combined co-citation and word analysis. II: dynamical aspects. Journal of the American Society for Information Science 1991;42:252-66.

[11] Egghe L, Rousseau R. Co-citation, bibliographic coupling and a characterization of lattice citation networks. Scientometrics 2002; 55:349-61

[12] Van Raan AFJ, Van Leeuwen TN. Assessment of the scientific basis of interdisciplinary, applied research application of bibliometric methods in nutrition and food research. Research Policy 2002;31: 611-32.

[13] Carpenter M, Cooper M, Narin F. Linkage between basic research literature and patents. Research Management 1980;3:30-5. 
[14] Dasgupta P, David P. Toward a new economics of science. Research Policy 1994;23(5):487-521.

[15] Merton R. Priorities in scientific discovery: a chapter in the sociology of science. American Sociological Review 1957;22(6):635-59.

[16] Kohler R. The management of science: experience of Warren Weaver and the Rockefeller Foundation program in molecular biology. Minerva 1976;14:279-306.

[17] Almeida P, Kogut B. Localisation of knowledge and the mobility of engineers in regional networks. Management Science 1999;45(7): 905-17.

[18] McKelvey M. Co-evolution in commercialization of genetic engineering. Industrial and Corporate Change 1977;6(3):503-32.

[19] Mansfield E. Academic research underlying industrial innovations: sources, characteristics and financing. Review of Economics and Statistics 1995;77(1):55-65.

[20] Zucker L, Darby M, Brewer M. Intellectual human capital and the birth of US biotechnology enterprises. American Economic Review 1998;88:90-306.

[21] Henderson R, Cockburn I. Measuring competence? exploring firm effects in pharmaceutical research. Strategic Management Journal 1994; 15:63-75.

[22] Bozeman B. Technology transfer and public policy: a review of research and theory. Research Policy 2000;29:626-55.

[23] Jaffe AB. Real effects of academic research. American Economic Review 1998:79(5):957-70.

[24] Podolny JM, Hannan M, Stuart T. Networks, knowledge and niches: competition in the worldwide semiconductor industry (1994-1991). American Journal of Sociology 1996;102(3):659-89.
[25] Dosi G. Technological paradigms and technological trajectories: a suggested interpretation of the determinants and directions of technical change. Research Policy 1982;11(3):147-62.

[26] Lubango LM, Pouris A. Industry work experience and inventive capacity of South African academic researchers. Technovation 2007; 27(2):788-96.

Louis Mitondo Lubango is a researcher at the Institute for Technologica Innovation in South Africa. He specializes in technology management and policy studies. He is actively involved in mapping and modelling success factors and barriers to technology production and dissemination in public and private sectors; knowledge value collective; and science, technology, and innovation monitoring. He completed a Ph.D. in technology management and policy issues from the University of Pretoria, a M.Sc. in applied chemistry from the University of the Witwatersrand, Johannesburg, and a B.Sc. (Honours) in industrial chemistry from University of Burundi.

Anastassios Pouris is Director, Institute for Technological Innovation, University of Pretoria, South Africa. He specializes in science, technology, and innovation policy development studies, including assessments and priority-related exercises. He is professor of science and technology policy at the University of Pretoria. He is a consultant for a number of government departments in South Africa, and various international organizations. His educational background includes engineering at the University of Thessaloniki, Greece, and economics at the University of Surrey, Guildford. He received a Ph.D. from the University of Cape Town, South Africa. He has published many articles in international journals. 